\title{
Effect of Thermal Cycling on the Marginal Fit of Provisional Restorations Fabricated Using Three Different Materials: An In Vitro Study
}

\author{
Lokesh B Kanchan ${ }^{1}$, Basawakumar Majage ${ }^{2}$, Arati Hoskhande ${ }^{3}$, Manju George ${ }^{4}$
}

\begin{abstract}
Aim and objective: This study aimed to evaluate and compare the marginal fit of different provisional restorations before and after thermal cycling. Materials and methods: The study consisted of three main groups of provisional materials, i.e., bisphenol A-glycidyl methacrylate (Bis-GMA) resin (Protemp II), polymethylmethacrylate (PMMA) self-cure tooth-colored resin, and computer-aided design/computer-aided manufacturing (CAD/CAM) PMMA resin. The groups were further subdivided into 2 subgroups with each having 10 specimens. A typhodont mandibular right first molar was prepared for a full veneer restoration and was cast in a base metal alloy. Polyvinyl siloxane putty index of the master die was prepared and poured with die stone. The provisional crowns were fabricated on these dies and cemented. Conditioning of the specimens was done by storing them in artificial saliva for 10 days. Thermal cycling of the experimental group was done by immersing the samples in two temperature-controlled water baths; $5^{\circ} \mathrm{C}$ (cold bath) and $55^{\circ} \mathrm{C}$ (hot bath). The samples were tested by stereomicroscope to find the marginal discrepancies. Paired $t$-test was done to evaluate the change between baseline to follow-up. Intergroup comparison was analyzed using one-way ANOVA followed by post hoc Tukey's test to compare the mean of measurements.

Results: The mean marginal discrepancies were Protemp II $(21.8750 \pm 3.30 \mu \mathrm{m})$, CAD/CAM resin $(16.6500 \pm 8.14 \mu \mathrm{m})$, and self-cure tooth-colored resin $(24.2250 \pm 3.26 \mu \mathrm{m})$ for the provisional crowns. A significant difference was seen in the mean marginal discrepancy of crowns fabricated with Protemp II, CAD-CAM resin, and self-cure tooth molding powder $(p=0.013)$.

Conclusion: The types of materials and the thermal cycling process had a significant effect on the marginal gap of interim restorations. The Bis-GMA resin and CAD/CAM PMMA resin exhibited better marginal adaptability than the PMMA self-cure tooth-colored resin groups, both before and after thermal cycling.

Keywords: CAD/CAM PMMA resin, Marginal gap, Protemp II, Self-cure, Temporary restoration.

International Journal of Prosthodontics and Restorative Dentistry (2021): 10.5005/jp-journals-10019-1326
\end{abstract}

\section{INTRODUCTION}

Provisional restoration plays an important role in the long-term success of fixed partial restorations. These interim restorations are used individually on single or multiple prepared teeth or they may provide coverage for abutment teeth as part of a splint or fixed partial denture before placement of permanent prosthesis., ${ }^{1,2}$

Precise marginal adaptation leads to the success of provisional restoration as it promotes gingival health during the period between tooth preparation and placement of final restoration, and also helps in preventing pulpal damage from thermal, bacterial, and chemical insults. ${ }^{3}$ Marginal adaptation is a measure of the polymerization shrinkage, stress release, and plasticization of a material when a crown is cemented on a tooth for a period of time. A poorly adapted provisional restoration encourages plaque accumulation which leads to periodontal conditions ranging from gingival inflammation to periodontal breakdown, especially where finish line margins are placed equigingivally or subgingivally. ${ }^{4}$ Longterm dimensional stability of the provisional restoration in the oral environment is an important consideration for complex integrated treatment plans where the final restoration is delayed until the completion of periodontal, endodontic, and orthodontic therapy. ${ }^{5}$

Polymethylmethacrylate (PMMA) was formerly the most popular interim material used in clinical treatment because of its high strength, color stability, and ease of repair. ${ }^{6}$ Using computeraided design/computer-aided manufacturing (CAD/CAM) to fabricate interim prostheses is of importance as CAD/CAM interim
${ }^{1}$ Private Practitioner, Bengaluru, Karnataka, India

${ }^{2,3}$ Department of Prosthodontics, Crown and Bridge, HKES's S Nijalingappa Institute of Dental Science and Research, Kalaburagi, Karnataka, India

${ }^{4}$ Private Practitioner, Kottayam, Kerala, India

Corresponding Author: Manju George, Private Practitioner, Kottayam, Kerala, India, Phone: +918880157762, e-mail: manjuglams@gmail. com

How to cite this article: Kanchan LB, Majage B, Hoskhande A, et al. Effect of Thermal Cycling on the Marginal Fit of Provisional Restorations Fabricated Using Three Different Materials: An In Vitro Study. Int J Prosthodont Restor Dent 2021;11(3):119-124.

Source of support: Nil

Conflict of interest: None

materials are prefabricated from industrially polymerized blocks, which prevents heat of polymerization and shrinkage. Moreover, the use of optical impression making in CAD/CAM interim treatments avoids patient discomfort. Many techniques like the direct method, indirect method or relining, and injection of cold-cure acrylic resin to fabricate provisional restorations have been used for achieving good marginal adaptation of the provisional restoration. ${ }^{7}$

Moulding et al. ${ }^{6}$ showed that three techniques, direct and relined, indirect, and direct and not removed from the abutment, 
resulted in smaller marginal gaps when compared with the direct technique of on/off polymerization. Keyf and Anil ${ }^{8}$ included the factors of margin design and water sorption. Crowns with shoulder margins showed a substantial increase in the marginal gap after 7 days. Robinson and Hovijitra9 ${ }^{9}$ examined the effects of relining directly made provisional crowns on the marginal gap size.

The most commonly used material for the fabrication of provisional restorations is the PMMA self-cure resins and their varieties. Even though multiple literatures are presently discussing the merits of CAD/CAM interim restorations there are not many comparing it with the conventional materials routinely used. The current literature has limited studies which compared the three different materials used in this study.

This study aimed to evaluate the marginal fit of provisional restoration using CAD/CAM polymethylmethacrylate Protemp II and PMMA self-cure resin before and after thermal cycling.

\section{Materials and Methods}

The study was conducted in a private teaching institution in Kalaburagi, Karnataka with technical support provided by the University of Gulbarga. Ethical clearance was obtained by the institutional review board.

The study consist of three main groups of provisional materials, i.e., bisphenol A-glycidyl methacrylate (Bis-GMA Resin) (Protemp II, 3M ESPE, DMG, Germany), PMMA self-cure tooth-colored resin (Dental Product India Limited, India), and CAD/CAM PMMA resin (Amann Girrbach, AG, Ceramill Temp, Austria). The sample size for each group was 20 which was further divided into two subgroups with one subgroup being subjected to thermal cycling.

\section{Preparation of Master Die}

A typhodont mandibular right first molar tooth (Ivorine) was prepared for a complete crown restoration with a 1-mm chamfer finish line and a taper of approximately $6^{\circ}$. The prepared tooth was cast in the base metal alloy (Rexillium III; Jeneric/Pentron, Wallingford, CT, USA). The metal die was mounted in dental stone in the form of a cylinder, $20 \mathrm{~mm}$ in diameter and $15 \mathrm{~mm}$ in height (Fig. 1). A custom tray was fabricated using a wax spacer and autopolymerizing acrylic resin.

After applying tray adhesive (Dentsply, De Trey GmgH Konstanz, Germany), 10 conventional impressions were made of the master die, by using polyvinyl siloxane (PVS) impression material (Dentsply,

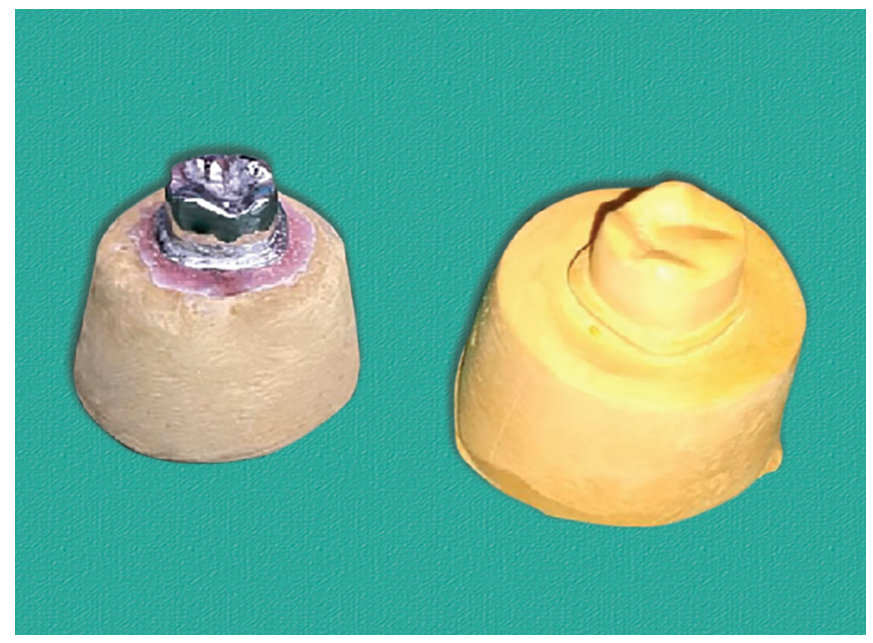

Fig. 1: Metal master die and stone replica
De Trey GmgH Konstanz, Germany). The impressions were poured with type IV dental stone (Fig. 2) and 60 models were obtained.

\section{Fabrication of Bis-GMA Resin Provisional Crowns}

A stent was made of self-cure clear acrylic resin over the unprepared dies. It was smeared with petroleum jelly and filled with the required amount of Bis-GMA Resin (Protemp II) and was placed onto the prepared dies and light-cured for 10 second/unit and then removed and final light-cured for 20 second/surface.

\section{Fabrication of PMMA Self-cure Tooth-Colored Resin Provisional Crowns}

An index of the unprepared artificial tooth (Ivorine) before preparation was made using putty polyvinylsiloxane impression material (Dentsply, De Trey GmgH Konstanz, Germany). A thin layer of separating medium was applied to the stone replica of prepared dies. Autopolymerizing resin was mixed in powder:liquid ratio of 3:1, placed in the impression, and was seated on the dies representing the prepared teeth. A rubber band was placed around the base and impression assembly and allowed to harden. Once the resin was hard, the putty index was separated from the stone replica, and the flash was neatly trimmed under magnification. The restorations were then seated on the respective dies.

\section{Fabrication of CAD/CAM PMMA Resin Provisional Crowns}

CEREC InEos system (Sirona, Bensheim, Germany) was used for scanning the preparation. The preparation was powdered with scan spray (Vita Zahnfabrik, Germany) using a propellant to provide a thin, even layer of powder. The preparation was then scanned and the crown was designed using the CEREC 3D v3.60 software. The CAD/CAM provisional blocks (acrylate polymer material; VITA CADTemp ${ }^{\oplus}$; VITA Zahnfabrik, Germany) were used and 10 provisional crowns were milled. The correlation model was used with the spacer set at $10 \mu \mathrm{m}$ for the CAD/CAM group and the default milling burs (1.2 mm cylinder bur, step bur) were used for the milling of the crowns. Following milling, the restorations were examined for the presence of any defects or cracks.

\section{Thermal Cycling}

The provisional restorations were cemented on the stone replicas using non-eugenol-based temporary cement (Temp Bond-NE, Brea, CA, USA). Equal quantities of the base and catalyst material

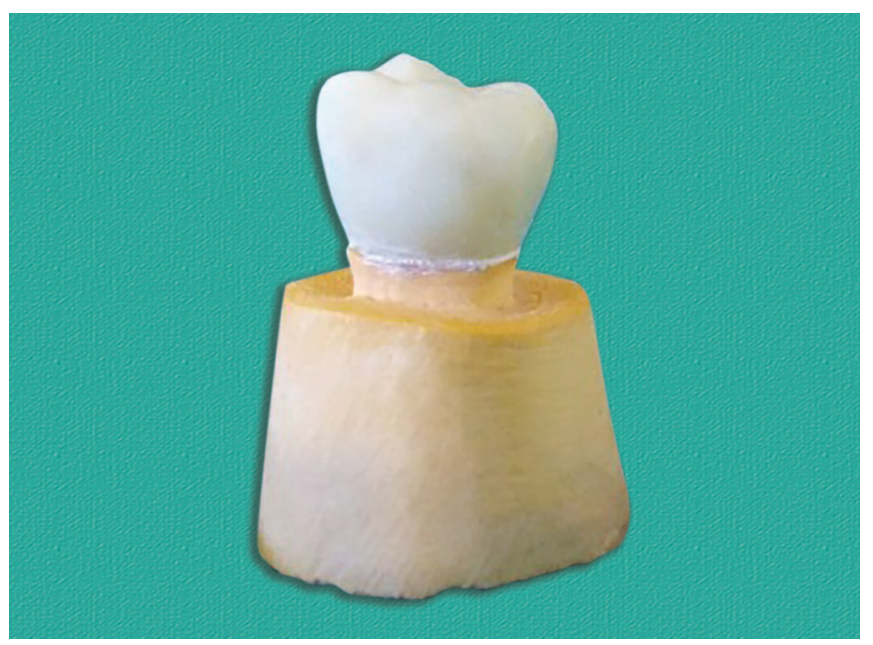

Fig. 2: Cementation of provisional crowns on master cast done 
were taken and mixed thoroughly for 30 seconds. A thin layer was smeared on the inner aspect of the restorations. The provisional restorations were then seated on the respective master dies (Fig. 2).

Ten specimens of each group were tested for marginal adaptation before thermal cycling and 10 were subjected to thermal cycling. The group subjected to thermal cycling was soaked in artificial saliva at $37^{\circ} \mathrm{C}$ for 14 days and then subjected to thermal cycling. Thermal cycling of the experimental specimens was done by immersing the samples in two temperature-controlled water baths maintained at $5^{\circ} \mathrm{C}$ (cold bath) and $55^{\circ} \mathrm{C}$ (hot bath). The samples of each group were packed in separate color-coded bags. These bags were put in cold and hot water baths alternatively and the dwell time was 6 seconds in each water bath. A total of 2,500 cycles were carried out similarly.

\section{Measurement of Marginal Accuracy}

The crowns were sectioned mesiodistally and buccolingually. The margins of the two sides of each section (buccal, mesial, palatal, and distal, depending on the section) were measured using stereomicroscope measurement software after scanning with the stereomicroscope (Leica Microsystems Ltd., DFC 290, Mumbai, India) at $4 \times$ magnification by one examiner who was blinded to the study (Fig. 3). There were three groups with two subgroups containing 10 specimens each, resulting in 240 sections and 240 marginal measurements. Measurements were made at the margins as the shortest distance from the internal surface of the crown to the prepared tooth surface close to the preparation finish line, representing the marginal gap according to Holmes et al. ${ }^{10}$

\section{Statistical Analysis}

The data were entered in Microsoft excel format and were analyzed using SPSS version 21 (IBM SPSS Corp. Ltd., Armonk, NY, USA). The continuous data were represented as mean \pm SD. Paired $t$-test was applied to evaluate the change between baseline to follow-up. Intergroup comparison was analyzed using one-way ANOVA followed by a post hoc Tukey's test to compare the mean of measurements. $p$ value $<0.05$ is considered as significant.

\section{Results}

The mean marginal fit of various groups before and after thermal cycling is shown in Table 1 and Fig. 4. The marginal fit was highest for CAD/CAM resin before $(52.47 \pm 3.56 \mu \mathrm{m})$ and after thermal cycling $(69.12 \pm 5.92 \mu \mathrm{m})$ compared with Protemp II and PMMA self-cure tooth-colored resin. Comparison of marginal fit before and after thermal cycling at mesial, distal, buccal and lingual side with Protemp II is presented in Table 2. Comparison of marginal fit before and after thermal cycling at mesial, distal, buccal and lingual side with CAD/CAM resin is presented in Table 3. Comparison of marginal fit before and after thermal cycling at mesial, distal, buccal and lingual side with PMMA self-cure tooth-colored rsein is presented in Table 4. Polymethylmethacrylate self-cure tooth-colored resin had the least marginal fit $(123.40 \pm 5.83 \mu \mathrm{m})$ of all the three groups on the four sides evaluated after thermal cycling.

An overall significant difference was seen in the marginal fit of three study groups when compared using one-way ANOVA as $p<$ 0.05 . Significant differences were seen in the marginal fit of all three study groups post thermal cycling when compared using paired $t$-test as $p<0.05$ (Table 4). Post hoc comparison using Tukey's test showed that marginal fit of CAD/CAM was found to be significantly more than Protemp II and marginal fit of Protemp II was found to be significantly more than PMMA self-cure tooth-colored resin (Table 5 and Fig. 5).

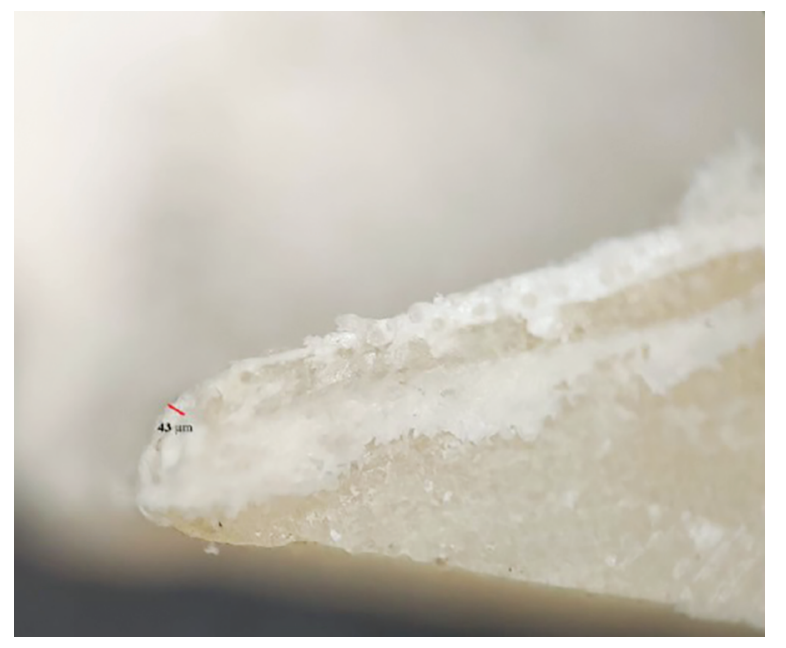

Fig. 3: Measurement of marginal discrepancy through the stereomicroscope at $4 \times$ magnification

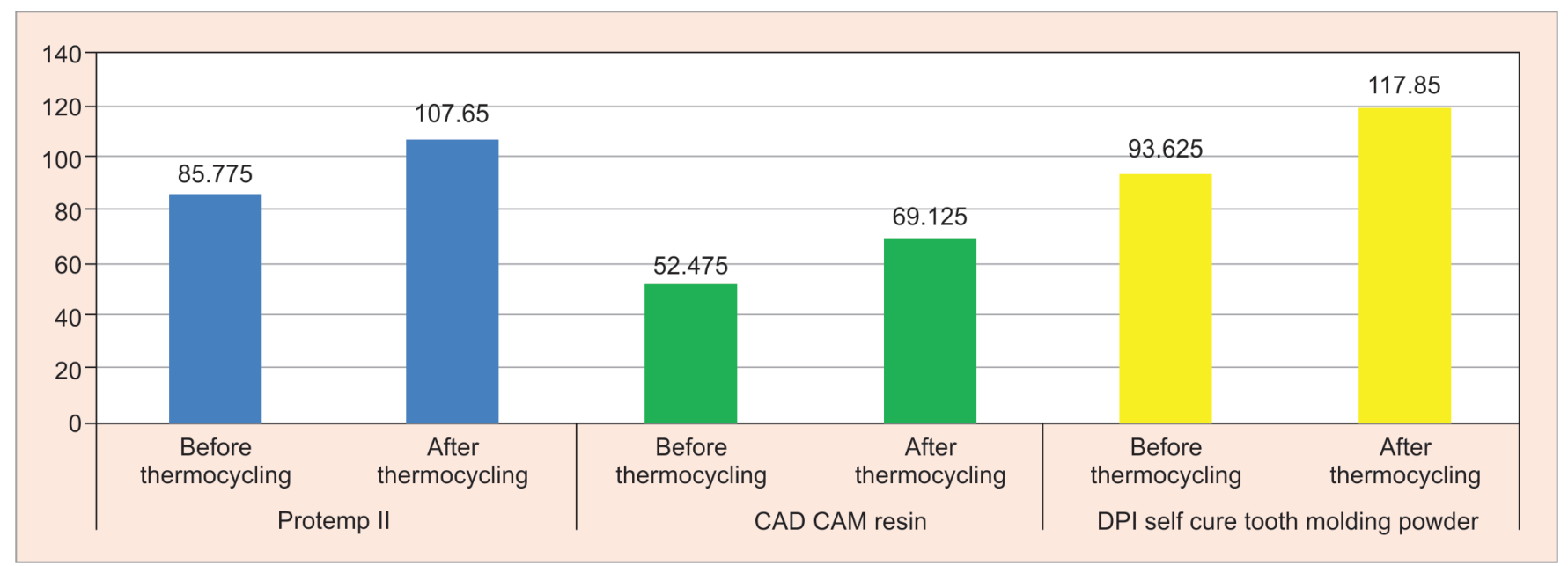

Fig. 4: Pre- to post-thermal cycling comparison of marginal fit 
Effect of Thermal Cycling on the Marginal Fit of Provisional Restorations Fabricated Using Three Different Materials

Table 1: Comparison of marginal fit before and after thermal cycling

\begin{tabular}{|c|c|c|c|c|c|c|}
\hline & & Mean & $N$ & Std. deviation & Std. error mean & $p$ value \\
\hline \multirow[t]{2}{*}{ Protemp II } & Before thermal cycling & 85.7750 & 10 & 2.79496 & 0.88384 & $<0.0001$ \\
\hline & After thermal cycling & 107.6500 & 10 & 2.92071 & 0.92361 & \\
\hline \multirow[t]{2}{*}{ CAD CAM resin } & Before thermal cycling & 52.4750 & 10 & 3.56575 & 1.12759 & $<0.0001$ \\
\hline & After thermal cycling & 69.1250 & 10 & 5.92576 & 1.87389 & \\
\hline \multirow[t]{2}{*}{ PMMA self-cure tooth-colored resin } & Before thermal cycling & 93.6250 & 10 & 2.20558 & 0.69747 & $<0.0001$ \\
\hline & After thermal cycling & 117.8500 & 10 & 1.58640 & 0.50166 & \\
\hline
\end{tabular}

Table 2: Comparison of marginal fit of Protemp II before and after thermal cycling on mesial, distal, buccal and lingual side

\begin{tabular}{|c|c|c|c|c|c|c|c|}
\hline & & Mean & Std. deviation & Std. error mean & Mean difference & Std dev & $p$ value \\
\hline \multirow[t]{2}{*}{ Mesial } & Before & 87.300 & 6.0928 & 1.9267 & 21.0000 & 7.7460 & $<0.0001$ \\
\hline & After & 108.300 & 10.0449 & 3.1765 & & & \\
\hline \multirow[t]{2}{*}{ Distal } & Before & 85.400 & 6.4670 & 2.0450 & 20.6000 & 6.5013 & $<0.0001$ \\
\hline & After & 106.000 & 8.4063 & 2.6583 & & & \\
\hline \multirow[t]{2}{*}{ Buccal } & Before & 84.600 & 7.8486 & 2.4819 & 25.9000 & 8.4650 & $<0.0001$ \\
\hline & After & 110.500 & 8.4492 & 2.6719 & & & \\
\hline \multirow[t]{2}{*}{ Lingual } & Before & 85.800 & 7.1616 & 2.2647 & 20.0000 & 11.2250 & $<0.0001$ \\
\hline & After & 105.800 & 9.4375 & 2.9844 & & & \\
\hline
\end{tabular}

Table 3: Comparison of marginal fit of CAD/CAM resin before and after thermal cycling on mesial, distal, buccal and lingual side

\begin{tabular}{|c|c|c|c|c|c|c|c|}
\hline & & Mean & Std. deviation & Std. error mean & Mean difference & Std dev & $p$ value \\
\hline \multirow[t]{2}{*}{ Mesial } & Before & 51.800 & 3.9944 & 1.2632 & 10.8000 & 4.9621 & $<0.0001$ \\
\hline & After & 62.600 & 6.0773 & 1.9218 & & & \\
\hline \multirow[t]{2}{*}{ Distal } & Before & 52.400 & 5.9104 & 1.8690 & 15.6000 & 8.6049 & $<0.0001$ \\
\hline & After & 68.000 & 6.8799 & 2.1756 & & & \\
\hline \multirow[t]{2}{*}{ Buccal } & Before & 53.800 & 11.0030 & 3.4795 & 21.3000 & 21.2396 & $<0.0001$ \\
\hline & After & 75.100 & 13.4367 & 4.2491 & & & \\
\hline \multirow[t]{2}{*}{ Lingual } & Before & 51.900 & 4.3321 & 1.3699 & 18.9000 & 9.9270 & $<0.0001$ \\
\hline & After & 70.800 & 8.7914 & 2.7801 & & & \\
\hline
\end{tabular}

Table 4: Comparison of marginal fit of PMMA self-cure tooth-colored resin before and after thermal cycling on mesial, distal, buccal and lingual side

\begin{tabular}{|c|c|c|c|c|c|c|c|}
\hline & & Mean & Std. deviation & Std. error mean & Mean difference & Std dev & $p$ value \\
\hline \multirow[t]{2}{*}{ Mesial } & Before & 92.000 & 6.4464 & 2.0385 & 28.2000 & 9.6356 & $<0.0001$ \\
\hline & After & 120.200 & 5.1812 & 1.6384 & & & \\
\hline \multirow[t]{2}{*}{ Distal } & Before & 94.700 & 5.5187 & 1.7452 & 16.0000 & 10.8423 & 0.009 \\
\hline & After & 110.700 & 5.9638 & 1.8859 & & & \\
\hline \multirow[t]{2}{*}{ Buccal } & Before & 94.100 & 5.4863 & 1.7349 & 29.3000 & 8.3540 & $<0.0001$ \\
\hline & After & 123.400 & 5.8348 & 1.8451 & & & \\
\hline \multirow[t]{2}{*}{ Lingual } & Before & 93.700 & 6.5668 & 2.0766 & 23.4000 & 12.3666 & 0.012 \\
\hline & After & 117.100 & 6.9514 & 2.1982 & & & \\
\hline
\end{tabular}

Table 5: Intergroup comparison of overall marginal fit of CAD/CAD, Protemp II, and PMMA self-cure tooth-colored resin

\begin{tabular}{|c|c|c|c|c|c|c|c|c|}
\hline & \multirow[b]{2}{*}{$N$} & \multirow[b]{2}{*}{ Mean } & \multirow[b]{2}{*}{ Std. deviation } & \multirow[b]{2}{*}{ Std. error } & \multicolumn{2}{|c|}{ 95\% confidence interval for mean } & \multirow[b]{2}{*}{ Minimum } & \multirow[b]{2}{*}{ Maximum } \\
\hline & & & & & Lower bound & Upper bound & & \\
\hline Protemp II & 10 & 21.8750 & 3.30876 & 1.04632 & 24.2419 & 19.5081 & 27.75 & 17.75 \\
\hline CAD CAM resin & 10 & 16.6500 & 8.14043 & 2.57423 & 22.4733 & 10.8267 & 34.00 & 2.00 \\
\hline $\begin{array}{l}\text { PMMA self-cure } \\
\text { tooth-colored resin }\end{array}$ & 10 & 24.2250 & 3.26907 & 1.03377 & 26.5636 & 21.8864 & 29.00 & 18.25 \\
\hline$p$ value & $0.013^{*}$ & & & & & & & \\
\hline Post hoc & $3>1>2$ & & & & & & & \\
\hline
\end{tabular}




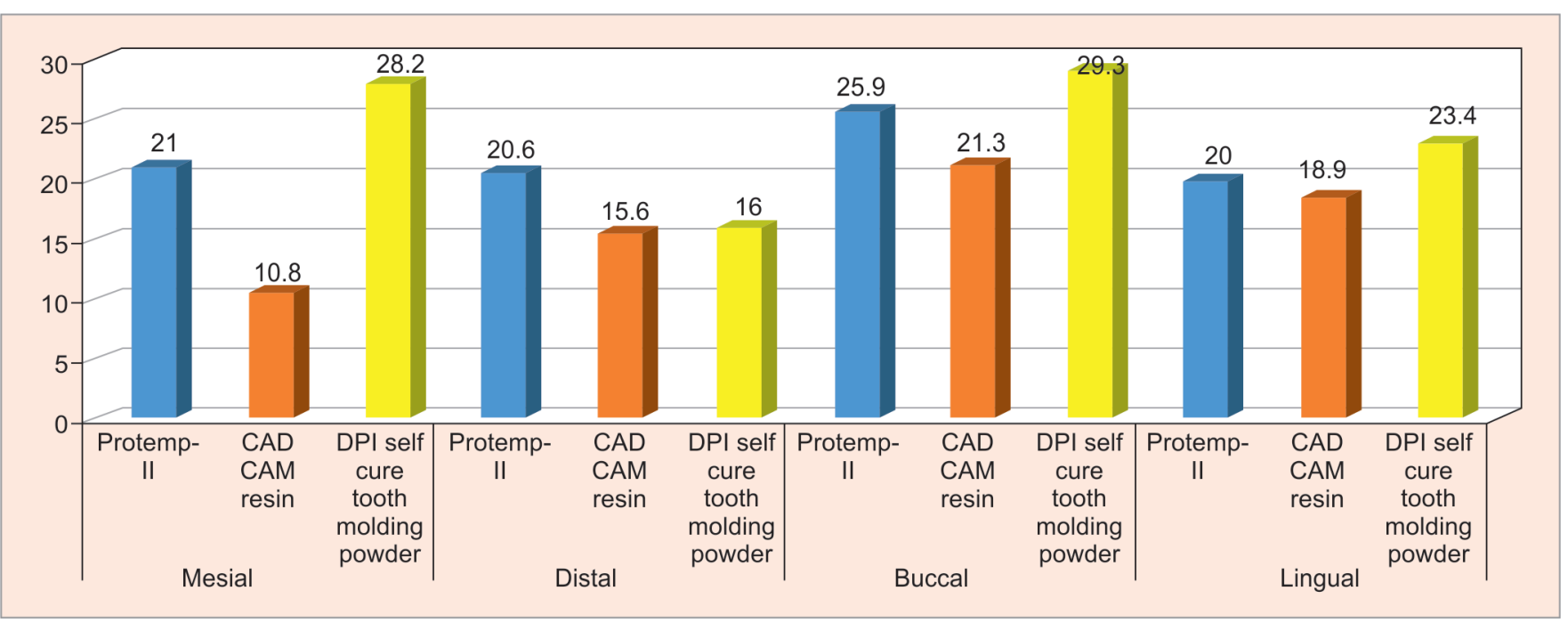

Fig. 5: Intergroup comparison of marginal fit of CAD/CAD, Protemp II, and DPI self-cure tooth molding powder from before thermal cycling to thermal cycling on mesial, distal, buccal and lingual side

\section{Discussion}

The marginal gap can be measured using different in vitro methods, which include direct visualization, silicone replica technique, and die sectioning methods. The die sectioning method is destructive compared with the other two methods but the cementation method allows for the simulation of intraoral conditions better since the crowns are cemented in the oral cavity.

Close marginal adaptation of a provisional resin crown to the finish line of a prepared tooth protects the pulp from the thermal, bacterial, and chemical insults. To conquer these insults, materials for provisional restorations with improved physical properties are available which emphasizes the marginal accuracy of provisional restorations.

Limited literature is available which assessed the degree of marginal gap formation of monomethacrylates and bis-acryl composite materials. Results of these studies show contradictory results. Some studies indicate that monomethacrylates have lower marginal discrepancies when compared with dimethacrylates, ${ }^{1,11}$ a few of them show a comparable fit between both the types, 3,4 while one study reported bis-acryl composite resins to be superior to methacrylate resin. One of the innate properties of polymerbased provisional materials is the polymerization shrinkage which causes dimensional changes which adversely affect precise fit (marginal discrepancies and occlusal interferences) and leads to internal stresses within the restorations. ${ }^{5,12}$ Clinicians are expected to construct provisional crowns with acceptable occlusion, contour, marginal adaptation, and finish. The results of the present study indicated that conventionally fabricated interim restorations showed a significantly larger mean marginal gap than their CAD/CAM fabricated counterparts, which was consistent with previous studies. ${ }^{2,13,14}$ Polymerization shrinkage is one cause of the dimensional changes that can adversely affect marginal gap ${ }^{15-18}$ and occurs with directly made interim restorations. ${ }^{16,18}$ This problem has a greater impact with PMMA resin, while it is comparatively lower but still observable with bis-acryl resin. ${ }^{16,18,19}$ Polymerization shrinkage is less of a problem with CAD/CAM interim restorations, either because the high-density CAD/CAM PMMA block was prepolymerized during the industrial fabrication process. ${ }^{14,20,21}$ This may be why CAD/CAM milled gap compared with conventionally fabricated materials.
The mean marginal discrepancy of Protemp II before and after thermal cycling on mesial, buccal, distal, and lingual sides presented a significant difference $(p<0.05)$. The mean marginal values were significantly lower with the Protemp II before thermal cycling $(85.775 \mu \mathrm{m})$ when compared with after thermal cycling $(107.65 \mu \mathrm{m})$. Before thermal cycling, the highest marginal value found was 87.300 $\mu \mathrm{m}$ on the mesial side and the least was $84.600 \mu \mathrm{m}$ on the buccal side. After thermal cycling, the highest marginal value found was $110.500 \mu \mathrm{m}$ on the buccal side and the least was $105.800 \mu \mathrm{m}$ on the lingual side. Other studies also reported similar results. In the study by Yao et al., ${ }^{2}$ the authors found that the mean marginal values were lower with the Protemp II before thermal cycling $(0.27 \pm 0.04 \mathrm{~mm})$ when compared with after thermal cycling $(0.40 \pm 0.06 \mathrm{~mm})$ and in the study reported by Angwarawong et al., ${ }^{22}$ they found that the mean marginal values were lower with the Protemp II before thermal cycling $(88 \pm 17 \mu \mathrm{m})$ when compared with after thermal cycling $(109 \pm 15 \mu \mathrm{m})$.

The mean marginal discrepancy of CAD/CAM PMMA before and after thermal cycling on mesial, buccal, distal, and lingual sides presented a significant difference $(p<0.05)$. The mean marginal values were significantly lower with the CAD/CAM resin before thermal cycling $(52.475 \mu \mathrm{m})$ when compared with after thermal cycling $(55.175 \mu \mathrm{m})$. Before thermal cycling, the highest marginal value found was $53.800 \mu \mathrm{m}$ on the buccal side and the least was $51.800 \mu \mathrm{m}$ on the mesial side. After thermal cycling, the highest marginal value found was $75.100 \mu \mathrm{m}$ on the buccal side and the least was $62.600 \mu \mathrm{m}$ on the mesial side. Similar results were obtained by other authors. In the study reported by Angwarawong et al., ${ }^{22}$ they found that the mean marginal values were lower with the CAD/CAM resin before thermal cycling $(54 \pm 8 \mu \mathrm{m})$ when compared with after thermal cycling (74 \pm $9 \mu \mathrm{m})$. In another study reported by Yao et al., ${ }^{2}$ the authors found that the mean marginal values were lower with the CAD/CAM resin before thermal cycling $(0.15 \pm 0.03 \mathrm{~mm})$ when compared with after thermal cycling $(0.17 \pm 0.03 \mathrm{~mm})$; however, no significant differences were observed.

The mean marginal discrepancy of PMMA self-cure toothcolored resin before and after thermal cycling on mesial, buccal, distal, and lingual sides presented a significant difference $(p<$ 0.05). The mean marginal values were significantly lower with the 
self-cure tooth-colored resin before thermal cycling $(93.625 \mu \mathrm{m})$ when compared with after thermal cycling $(117.85 \mu \mathrm{m})$. Before thermal cycling, the highest marginal value found was $94.700 \mu \mathrm{m}$ on the distal side and the least was $92.000 \mu \mathrm{m}$ on the mesial side. After the thermal cycling group, the highest marginal value found was $123.400 \mu \mathrm{m}$ on the buccal side and the least was $117.100 \mu \mathrm{m}$ on the lingual side. Similar results were reported by Ehrenberg et al. ${ }^{23}$ They found that the mean marginal values were lower with the PMMA self-cure tooth-colored resin before thermal cycling (323.4 $\pm 98.4 \mu \mathrm{m})$ when compared with after thermal cycling $(499.1 \pm 192.3 \mu \mathrm{m})$.

The study by Angwarawong et al. ${ }^{22}$ found that the mean marginal values were significantly lower with the CAD/CAM PMMA resin $(54 \pm 8 \mu \mathrm{m})$ compared with Bis-GMA resin $(88 \pm 17 \mu \mathrm{m})$, both before and after thermal cycling. In the study reported by Yao et al. $^{2}$ the authors reported that the mean marginal values were lower with the CAD/CAM resin before thermal cycling $(0.15 \pm 0.03$ $\mathrm{mm})$ when compared with after thermal cycling $(0.17 \pm 0.03 \mathrm{~mm})$. Significant differences were observed in the marginal accuracy for bis-acryl resin composites but not for CAD/CAM resin.

In the present study, the marginal gap significantly increased after thermal cycling. But all the values were within the acceptable range of $<120 \mu \mathrm{m}$. In this study, thermal cycling is taken as 6 months of intraoral usage. The limitations of the present study are that thermal cycling alone cannot alone be taken as a parameter that affects the marginal gap of provisional restorations. Masticatory forces, enzymatic degradations, etc., should be taken into account to determine the change in the marginal gap of provisional restorations after long-term service.

\section{Conclusion}

Within limitations of this study, the following conclusions can be drawn:

- The types of materials and the thermal cycling process had a significant effect on the marginal gap of interim restorations. Moreover, the interaction of both factors significantly influenced the marginal gap of interim restorations.

- The Bis-GMA resin and CAD/CAM PMMA resin exhibited better marginal adaptability than the PMMA self-cure tooth-colored resin crowns, both before and after thermal cycling.

- All interim restoration groups were significantly affected by the thermal cycling.

\section{References}

1. Digholkar S, Madhav VN, Palaskar J. Evaluation of the flexural strength and microhardness of provisional crown and bridge materials fabricated by different methods. J Indian Prosthodon Soc 2016;16(4):328. DOI: 10.4103/0972-4052.191288.

2. Yao J, Li J, Wang Y, et al. Comparison of the flexural strength and marginal accuracy of traditional and CAD/CAM interim materials before and after thermal cycling. J Prosthet Dent 2014;112(3):649-657. DOI: 10.1016/j.prosdent.2014.01.012.

3. Nejatidanesh F, Azadbakht K, Savabi O, et al. Effect of repeated firing on the translucency of CAD-CAM monolithic glass-ceramics. J Prosthet Dent 2020;123(3):530.e1-530.e6. DOI: 10.1016/j.prosdent.2019.10.028.

4. Ehrenberg DS, Weiner S. Changes in marginal gap size of provisional resin crowns after occlusal loading and thermal cycling. J Prosthet Dent 2000;84(2):139-148. DOI: 10.1067/mpr.2000.108027.
5. Koumjian JH, Holmes JB. Marginal accuracy of provisional restorative materials. J Prosthet Dent 1990;63(6):639-642. DOI: 10.1016/00223913(90)90320-c.

6. Moulding MB, Loney RW, Ritsco RG. Marginal accuracy of provisional restorations fabricated by different techniques. Int J Prosthodont 1994;7(5):468-472.

7. Gujjari AK, Bhatnagar VM, Basavaraju RM. Color stability and flexural strength of poly (methyl methacrylate) and bis-acrylic composite based provisional crown and bridge auto-polymerizing resins exposed to beverages and food dye: an in vitro study. Indian J Dent Res 2013;24(2):172. DOI: 10.4103/0970-9290.116672.

8. Keyf F, Anil N. The effect of margin design on the marginal adaptation of temporary crowns. J Oral Rehabil 1994;21(4):367-371. DOI: 10.1111/ j.1365-2842.1994.tb01151.x.

9. Robinson FB, Hovijitra S. Marginal integrity of direct temporary crowns. J Prosthet Dent 1982;47(4):390-392. DOI: 10.1016/s00223913(82)80087-5.

10. Holmes JR, Bayne SC, Holland GA, et al. Considerations in measurement of marginal fit. J Prosthet Dent 1989;62(4):405-408. DOI: 10.1016/0022-3913(89)90170-4.

11. Shillingburg HT, Hobo S, Whitsett LD. Fundamentals of fixed prosthodontics. 4rd ed., Quintessence Publishing CO, Inc; 2012.

12. Christensen GJ. The fastest and best provisional restorations. J Am Dent Assoc 2003;134(5):637-639. DOI: 10.14219/jada. archive.2003.0233.

13. Abdullah AO, Tsitrou EA, Pollington S. Comparative in vitro evaluation of CAD/CAM vs conventional provisional crowns. J Appl Oral Sci 2016;24(3):258-263. DOI: 10.1590/1678-775720150451.

14. Mai HN, Lee KB, Lee DH. Fit of interim crowns fabricated using photopolymer-jetting 3D printing. J Prosthet Dent 2017;118(2):208215. DOI: 10.1016/j.prosdent.2016.10.030.

15. Rakhshan V. Marginal integrity of provisional resin restoration materials: a review of the literature. Saudi J Dent Res 2015;6(1):33-40. DOI: 10.1016/j.sjdr.2014.03.002.

16. Balkenhol M, Knapp M, Ferger $P$, et al. Correlation between polymerization shrinkage and marginal fit of temporary crowns. Dent Mater 2008;24(11):1575-1584. DOI: 10.1016/j.dental.2008. 07.001 .

17. Dureja I, Yadav B, Malhotra P, et al. A comparative evaluation of vertical marginal fit of provisional crowns fabricated by computeraided design/computer-aided manufacturing technique and direct (intraoral technique) and flexural strength of the materials: an in vitro study. J Indian Prosthodont Soc 2018;18(4):314-320. DOI: 10.4103/jips. jips_306_17.

18. Amin BM, Aras MA, Chitre V. A comparative evaluation of the marginal accuracy of crowns fabricated from four commercially available provisional materials: an in vitro study. Contemp Clin Dent 2015;6(2):161-165. DOI: 10.4103/0976-237X.156035.

19. Kim SH, Watts DC. Polymerization shrinkage-strain kinetics of temporary crown and bridge materials. Dent Mater 2004;20(1):88-95. DOI: 10.1016/s0109-5641(03)00101-5.

20. Edelhoff D, Beuer F, Schweiger J, et al. CAD/CAM-generated highdensity polymer restorations for the pretreatment of complex cases: a case report. Quintessence Int 2012;43(6):457-467.

21. Elagra MI, Rayyan MR, Alhomaidhi MM, et al. Color stability and marginal integrity of interim crowns: an in vitro study. Eur J Dent 2017;11(3):330-334. DOI: 10.4103/ejd.ejd_66_17.

22. Angwarawong $T$, Reeponmaha $T$, Angwaravong O. Influence of thermomechanical aging on marginal gap of CAD-CAM and conventional interim restorations. J Prosthet Dent 2020;124(5):566-e1. DOI: 10.1016/j.prosdent.2020.03.036.

23. Ehrenberg $D$, Weiner $\mathrm{Gl}$, Weiner $\mathrm{S}$. Long-term effects of storage and thermal cycling on the marginal adaptation of provisional resin crowns: a pilot study. J Prosthet Dent 2006;95(3):230-236. DOI: 10.1016/j.prosdent.2005.12.012. 